\title{
ANALISIS KEMAMPUAN KIDS ATHLETICS PADA SISWA SEKOLAH DASAR DI KOTA BENGKULU
}

\author{
Dita Hindriani \\ PENJAS FKIP UNIB, e-mail: Dythahindriani@yahoo.com \\ Sugiyanto \\ Universitas Bengkulu \\ Syafrial \\ Universitas Bengkulu
}

\begin{abstract}
Abstrak
Penelitian ini bertujuan untuk mendapatkan gambaran mengenai kemampuan Kids Athletics Pada Siswa Sekolah Dasar di Kota Bengkulu. Jenis penelitian adalah deskriptif kuantitatif dengan tujuan untuk mengungkapkan atau menyelidiki suatu keadaan yang sebenarnya. Populasi yang digunakan dalam penelitian ini adalah siswa sekolah dasar Kota Di Bengkulu. Sampel penelitian adalah empat sekolah dasar yaitu SDN 19, SDN 74, SDN 02, dan SDN 01 sebanyak 129 siswa. Instrumen tes yang digunakan dalam penelitian yaitu kanga's excape, lompat katak, lempar turbo dan formula 1, pada instrumen ini pelaksanaan tes Kids Athletics dilakukan 2 kesempatan ,hasil baik dar kedua kesempatan diambil sebagai skor terbaik yang diperoleh masin-masing teste. Teknik pengumpulan data penelitian menggunakan tes dan pengukuran terhadap sampel. Teknik analisis data menggunakan deskriptif persentase. Berdasarkan hasil penelitian diketahui bahwa kemampuan Kids athletics SDN 19 Kota Bengkulu anak laki-laki berkategori kurang (46,7\%), sedangkan anak perempuan berkategori sedang (36,4\%). Pada SDN 74 Kota Bengkulu anak laki-laki berkategori kurang $(56,25 \%)$, sedangkan anak perempuan berkategori kurang $(53,8 \%)$. Pada SDN 02 Kota Bengkulu anak laki-laki berkategori sangat kurang (90\%), sedangkan anak perempuan berkategori sangat kurang (55\%). Pada SDN 01 Kota Bengkulu anak laki-laki berkategori sangat kurang (90,9\%), sedangkan anak perempuan berkategori sangat kurang (58,3\%). Kemampuan Kids Athletics Seluruh Sekolah Dasar Kota Bengkulu berkategori sangat kurang (44,9\%)
\end{abstract}

Kata kunci: Analisis, Kids Athletics, siswa SD.

\begin{abstract}
This study aims to get an idea of the ability of kids athleics on the elementary school students in the city of bengkulu. This type of research is descriptive quantitav with the intention to reveal or investigate the real thing. The population used in this research of elementary school in Bengkulu city. The research sample is four primary school namely SDN 19, SDN 74, SDN 02,dan SDN 01 as many as 129 students. Instrument the test used are kanga's excape, jumping frog, throw a turbo and formula 1, In this instrument the implementation of the Kids Athletics test is done 2 chance, the good results of both opportunities are taken as the best score obtained by each
\end{abstract}


teste. Research data collection techniques using test and measurement to sample. The technique of data analysis using descripive percentage. Based on the survey results revealed that the abilitiy of Kids Athletics SDN 19 Bengkulu city boys category less $(46,7 \%)$, while the girls most of the category of being (36,4\%). At SDN 74 Bengkulu City boys mostly category less(56,25\%), while the girls most of the category of less $(53,8 \%)$. At SDN 02 Bengkulu City boys mostly category is very less (90\%), the girls most of the category is very less (55\%). At SDN 01 Bengkulu city the male of the category is very less $(90,9 \%)$, while the girls most of the category is very less $(58,3 \%)$. The ability of kids athletics all elementary school city bengkulu most of the category is very less $(44,9 \%)$

Keywords : Analysis, kids athletics, elementary school students

\section{PENDAHULUAN}

Olahraga sebagai salah satu aktivitas fisik yang sistematis yang memiliki tujuan untuk menyempurnaan, dalam melaksanakannya tanpa rasa takut dan penuh keberanian. Olahraga sekarang sangat digemari semua orang terutama anak-anak. Salah satunya cabang olahraga atletik yang merupakan gerak dasar. Atletik merupakan cabang olahraga paling tua. Atletik juga disebut mother of sport. Atletik merupakan aktivitas jasmani yang terdiri dari gerakan-gerakan dasar yang dinamis dan harmonis, yaitu jalan, lari, lompat, dan lempar (Giri wiarto (2013:1). Kids athletics suatu seperangkat alat yang ditujukan untuk aktivitas olahraga anak -anak.Kids athletics bertujuan untuk memenuhi minat anak-anak dalam aktivitas gerak, mengenalkan dasardasar gerakan atletik dalam bentuk permainan, merangsang pertumbuhan dan perkembangan jasmani serta memelihara kesehatan serta menghindari rasa bosan pada anak-anak. Berdasarkan hasil pengamatan obeservasi pada tanggal 20 januari 2017 yang penulis lakukan pada SD Negeri 74, SD Negeri 01, SD Negeri 02,dan SD Negeri 19 Kota Bengkulu bahwa kemampuan Kids athletics masih rendah.
Dilihat dari pembelajaran dasar Kids athletics yang jarang dikenalkan pada siswa SD karena kurangnya pengetahuan dan informasi penegasan dikomunitas guru pendidikan jasmani tentang materi Kids athletic dan kurangnya sarana dan prasarana yang ada di SD tersebut. Banyak sekali kompeteii/perlombaan anak-anak dalam olahraga salah satunya event O2SN tingkat SD. Dengan diadakan event tersebut kita bisa mengukur seberapa bagusnya kemampuan dan minat siswa sekolah dasar tersebut. Dari hasil O2SN tingkat SD cabang Kids athletics juga belum memperoleh hasil yang maksimal. Oleh karena itu, minat anak sekolah dasar pun sedikit dan prestasi pada anak yang mengikuti event banyak mengalami kegagalan dan merosotnya prestasi. Oleh karena itu, penerapan pelatihan Kids athletics untuk anak SD perlu dilakukan. Berdasarkan urian diatas peneliti tertarik untuk melakukan penelitian dengan judul "Analisis Kemampuan Kids Athletics Pada Siswa Sekolah Dasar Di Kota Bengkulu". Rumusan masalah yaitu: Bagaimana Kemampuan Kids Athletics Pada Siswa Sekolah Dasar Di Kota Bengkulu ?. Tujuan dalam penelitian yaitu untuk mengetahui kemampuan kids athletics pada siswa sekolah dasar sekota bengkulu, dengan item 
kanga's escape, loncat katak, lempar turbo dan formula 1. Sudah sejak dahulu kala anak-anak telah tertarik dan beminat terhadap bertanding / bersaing satu sama lain, dengan itu Atletik dengan beragam event yang dimilikinya. Dalam musim semi 2001, " Kelompok Kerja" Atletik Bocah IAAF" (IAAF KID'S ATHLETICS) mengambil prakarsa dan mengembangkan bahwa suatu konsepsi tentang event untuk anak-anak yang menggambarkan suatu keberangkatan nyata dari atletik model orang dewasa. Konsepsi ini mulai sekarang dan untuk selanjutnya diberi tanda/nama sebagai "Atletik Bocah-IAAF"(IAAF Kids' Athletics).

Menurut Suyono (2002: 5) Kid's athletics merupakan cabang olahraga atletik khusus teruntuk anak-anak yang di lakukan secara individu maupun kelompok dalam bentuk perlombaan sehingga melatih anak untuk berkompetisi dalam permainan yang menyenangkan. Peralatan yang digunakan dalam kid's athletics tidak seperti pada olahraga atletik dewasa namun disesuaikan karakteristik dan perkembangan anak, sehingga anak lebih mudah melakukan setiap gerakan-gerakan yang terdapat dalam gerak dasar atletik seperti gelang estafet, lembing anak (turbo), gawang, dan lompat. Jenis cabang olahraga ini diperkenalkan pertama kali oleh IAAF (International Association of Athletics Federation) kemudian disebarkan ke sekolah-sekolah dasar melalui pendidikan dan pelatihan oleh Pusat Pembinaan. Nomor-nomor Perlombaan Kid's Athletics dibagi menjadi 4 nomor perlombaan yaitu : kanga's excape, lompat katak, lempar turbo, dan formula 1. Atletik anak-anak dikelompokkan menjadi 3 (tiga) kelompok yaitu kelompok I untuk kelas I dan II, Kelompok II untuk kelas III dan IV, dan kelompok III untuk kelas $\mathrm{V}$ dan VI. Menurut Allen dan Marotz (2010: 204) Dillihat dari berbagai segi, anak usia 11-12 tahun adalah individu yang mudah disayangi. Mereka selalu ingin tau, enerjik, suka menolong, dan gembira. Anak usia 11-12 tahun ini senang mengikuti perkumpulan olahraga dan fisik. Pada usia ini anak telah membangun rasa percaya diri pada kemampuannya, keterampilan bahasa, metortik dan kognitif mereka telah mencapai kecanggihan orang dewasa.

\section{METODE}

Jenis penelitian ini adalah penelitian deskriptif kuantitatif. Tempat penelitian dilakukan di lapangan sekolah dasar yang diteliti, yaitu SDN 74, SDN 02, SDN 01, dan SDN 19. Penelitian dilakukan selama 1 Bulan pada semester genap tahun ajaran 2016/2017. Menurut Arikunto (2010: 173), Populasi adalah keseluruhan subyek penelitian, apabila seseorang ingin meneliti semua elemen yang ada dalam wilayah penelitian, maka penelitiannya merupakan penelitian populasi. Populasi dalam penelitian ini adalah seluruh siswa sekolah dasar di kota Bengkulu. Berdasarkan pembagian wilayah, kota Bengkulu terdiri dari 9 kecamatan dengan jumlah sekolah dasar sebanyak 84 sekolah (Dinas Pendidikan Kota Bengkulu, 2017).Sampel wilayah adalah teknik sampling yang dilakukan dengan mengambil wakil dari setiap wilayah yang terdapat dalam penelitian. Mengingat di kota Bengkulu terdapat 9 kecamatan, terdiri dari 4 kecamatan lama dan 5 kecamatan baru hasil pemekaran wilayah, maka wilayah penelitian mengambil 2 kecamatan lama dan 2 kecamatan baru, dengan setiap kecamatan diambil satu sekolah yang merupakan SD Inti dengan subyek siswa kelas $V$ yang dilakukan secara random, jadi sampel yang digunakan sebanyak 129 siswa. Penelitian ini menggunakan teknik pengumpulan data dengan cara tes dan pengukuran langsung 
terhadap sampel. Instrumen Kids athletics dalam penelitian ini dibuat atau dimodifikasi untuk mengukur kemampuan siswa secara individu bukan beregu.Penelitian ini menggunkan rangkaian tes Kids athletics yaitu 1. kanga excape Prosedur : Didalam kanga's excape kita modifikasi menjadi $20 \mathrm{~m}$ sprint dan $20 \mathrm{~m}$ dengan rintangan seperti gawang yang ditentukan jaraknya, Penilaian : Ranking dilakukan berdasarkan waktu yang terbaik dan peralatan digunakan stopwatch, lintasan 20m dan 2 gawang dan 2 tiang bendera, 2. Lompat katak Prosedur : Dari garis start seorang peserta melakukan "lompat katak" tiga kali berturut-turut dengan bertumpu dan mendarat dua kaki. Penilaian Setiap peserta memiliki 2 kesempatan melompat jarak terjauh yang dicapai peserta adalah hasilnya,dan peralatan yang digunakan meteran dan alat penanda. 3) Lempar turbo Prosedur : Lempar lembing anak-anak diawali dengan awalan 5 meter, setelah melakukan awalan pendek peserta melempar lembing anak ke area lemparan dengan dibatasi garis lempar. Setiap peserta melakukan dua lemparan, Penilaian Setiap lemparan diukur dengan memberi tanda yang ditarik 90 derajat kearah garis batas lempar dan dicatat jarak yang terbaik dari dua lemparan merupakan hasil dan peralatan digunakan 2 lembing turbo dan meteran. 4) Formula 1 Prosedur : Lari keliling lintasan sekitar 80 meter yang dibagi menjadi area lari sprint, lari gawang. Setiap peserta harus memulai rangkaian aktivitas dengan melakukan roll depan atau samping di atas matras, Penilaian : Rangking dilakukan dengan melihat catatan waktu yang dicapai oleh peserta, dan peralatan yang digunakan 9 gawang, 10 tongkat/tiang slalom (jarak 1 meter tiap tiang, martas, sekitar 30 kerucut/tanda dan stopwatch Setiap peserta harus melakukan aktivitas sepanjang lintasan secara lengkap. Menurut
Sugiyono (2012:121) Valid berarti instrumen tersebut dapat digunakan untuk mengukur apa yang seharusnya diukur. Dalam tes ini melakukan pendahuluan dengan instrumen yang digunakan memiliki angka validitas sebesar 0,98 untuk tes kanga's excape, untuk tes lompat katak sebesar 0,87, untuk tes lempar turbo sebesar 0,98 dan tes formula 1 sebesar 0,97, dan penelitian ini untuk menguji reliabilitas yang dipakai dalam pengumpulan data, maka sebelum melakukan penelitian di uji coba tes (Tes-Re tes) setelah diperoleh data tes-re tes kanga's excape dengan reliabilitas sebesar 0,95, untuk lompat katak dengan reliabilitas sebesar 0,96, untuk lempar turbo dengan reliabilitas sebesar 0,94 dan formula 1 dengan reliabilitas sebesar 0,88. Hasil tes diperoleh dari tiap-tiap item tes Kids athletics merupakan data kasar, selanjutnya data kasar tiap-tiap tes tersebut diberi skor pada setiap item, lalu keempat item dijumlahkan skornya menjadi total skor, lalu data diolah menggunakan teknik analisis data dengan rumus persentase

$\left(\mathrm{p}=\frac{f}{n} x 100 \%\right.$.).

\section{HASIL DAN PEMBAHASAN}

Hasil penelitian di sekolah dasar Kota Bengkulu bahwa kemampuan Kid's athletics pada siswa sekolah dasar yaitu:

1. SD Negeri 19 Kota Bengkulu

Tabel 1. Deskriptif hasil penelitian siswa kelas v SD N 19 Laki-laki

\begin{tabular}{c|c|c|c} 
Skor & kategori & frekuensi & $\mathbf{\%}$ \\
\hline $19-21$ & Sangat baik & 0 & 0 \\
\hline $16-18$ & Baik & 1 & 6,7 \\
\hline $13-15$ & sedang & 2 & 13,3 \\
\hline $10-12$ & kurang & 7 & 46,7 \\
\hline$\leq 9$ & $\begin{array}{l}\text { Sangat } \\
\text { kurang }\end{array}$ & 5 & 33,3 \\
\hline \multicolumn{2}{r|}{ Jumlah } & 15 & 100
\end{tabular}


Laki-laki yang masuk dalam kategori sangat baik sebanyak 0 siswa atau sebesar $0 \%$, kategori Baik sebanyak 1 siswa atau sebesar $6,7 \%$, kategori sedang sebanyak 2 siswa atau sebesar 13,3\%, kategori kurang sebanyak 7 siswa atau sebesar $46,7 \%$, dan kategori sangat kurang sebanyak 5 siswa atau sebesar $33,3 \%$.

Tabel 2 Deskriptif hasil penelitian siswa kelas v SD N 19 perempuan

\begin{tabular}{c|c|c|c} 
Skor & kategori & frekuensi & $\mathbf{\%}$ \\
\hline $18-20$ & Sangat baik & 0 & 0 \\
\hline $15-17$ & Baik & 1 & 4,55 \\
\hline $12-14$ & sedang & 9 & 40,9 \\
\hline $9-11$ & kurang & 8 & 36,4 \\
\hline$\leq 8$ & $\begin{array}{l}\text { Sangat } \\
\text { kurang }\end{array}$ & 4 & 18,1 \\
\hline \multicolumn{2}{r|}{ Jumlah } & 22 & 100
\end{tabular}

sedangkan untuk perempuan hasil tes kemampuan kids athletics yang masuk dalam kategori sangat baik sebanyak 0 siswa atau sebesar $0 \%$, kategori Baik sebanyak 1 siswa atau sebesar 4,5\%, kategori sedang sebanyak 9 siswa atau sebesar 40,9\%, kategori kurang sebanyak 8 siswa atau sebesar $36,4 \%$, dan kategori sangat kurang sebanyak 4 siswa atau sebesar $18,1 \%$.

Tabel 3. hasil penelitian kids athletics siswa

\begin{tabular}{c|c|c|c}
\multicolumn{4}{|c}{ kelas V SD N 19 Kota Bengkulu } \\
N0 & kategori & frekuensi & \% \\
\hline 1 & Sangat baik & 0 & 0 \\
\hline 2 & Baik & 2 & 5,4 \\
\hline 3 & sedang & 11 & 29,7 \\
\hline 4 & kurang & 15 & 40,5 \\
\hline 5 & Sangat kurang & 9 & 24,3 \\
\hline & Jumlah & 37 & 100
\end{tabular}

Hasil gabungan dari anak laki-laki dan perempuan bahwa hasil tes kemampuan kids athletics siswa kelas V SD Negeri 19 Kota Bengkulu yang masuk dalam kategori sangat baik sebanyak 0 siswa atau sebesar $0 \%$, kategori baik sebanyak 2 siswa atau sebesar $5,4 \%$, kategori sedang sebanyak 11 siswa atau sebesar 29,7\%, kategori kurang sebanyak 15 siswa atau sebesar 40,5\% dan kategori sangat kurang sebanyak 9 siswa atau sebesar $24,3 \%$.

2. SD Negeri 74 Kota bengkulu

Tabel 4. Deskriptif hasil penelitian siswa kelas V SD N 74 Laki-laki

\begin{tabular}{c|c|c|c} 
Skor & kategori & frekuensi & $\mathbf{\%}$ \\
\hline $19-21$ & Sangat baik & 0 & 0 \\
\hline $16-18$ & Baik & 2 & 12,5 \\
\hline $13-15$ & sedang & 2 & 12,5 \\
\hline $10-12$ & kurang & 9 & 56,25 \\
\hline$\leq 9$ & Sangat kurang & 3 & 18,75 \\
\hline \multicolumn{2}{r|}{ Jumlah } & 16 & 100
\end{tabular}

untuk laki-laki hasil tes kemampuan kids athletics yang masuk dalam kategori sangat baik sebanyak 0 siswa atau sebesar $0 \%$, kategori Baik sebanyak 2 siswa atau sebesar $12,5 \%$, kategori sedang sebanyak 2 siswa atau sebesar 12,5\%, kategori kurang sebanyak 9 siswa atau sebesar 56,25\%, dan kategori sangat kurang sebanyak 3 siswa atau sebesar $18,75 \%$.

Tabel 5 Deskriptif hasil penelitian siswa kelas v SD N 74 perempuan

\begin{tabular}{c|c|c|c} 
Skor & Kategori & frekuensi & $\mathbf{\%}$ \\
\hline $18-20$ & Sangat baik & 0 & 0 \\
\hline $15-17$ & Baik & 0 & 0 \\
\hline $12-14$ & sedang & 6 & 46,2 \\
\hline $9-11$ & kurang & 7 & 53,8 \\
\hline$\leq 8$ & $\begin{array}{l}\text { Sangat } \\
\text { kurang }\end{array}$ & 0 & 0 \\
\hline \multicolumn{2}{r|}{ Jumlah } & 13 & 100
\end{tabular}

untuk perempuan hasil tes kemampuan kids athletics yang masuk dalam kategori sangat baik sebanyak 0 siswa atau sebesar $0 \%$, kategori baik sebanyak 0 siswa atau sebesar 0\%, kategori sedang sebanyak 6 
siswa atau sebesar 46,2\%, kategori kurang sebanyak 7 siswa atau sebesar $53,8 \%$ dan kategori sangat kurang sebanyak 0 siswa atau sebesar $0 \%$.

Tabel 6. hasil penelitian kids athletics siswa kelas V SD N 74 Kota Bengkulu

\begin{tabular}{c|c|c|c} 
No & kategori & frekuensi & $\mathbf{\%}$ \\
\hline 1 & Sangat baik & 0 & 0 \\
\hline 2 & Baik & 2 & 6,9 \\
\hline 3 & sedang & 8 & 27,6 \\
\hline 4 & kurang & 16 & 55,2 \\
\hline 5 & Sangat kurang & 3 & 10,3 \\
\hline & Jumlah & 37 & 100
\end{tabular}

hasil gabungan anak laki-laki dan perempuan bahwa hasil tes kemampuan kids athletics siswa kelas V SD Negeri 74 Kota Bengkulu yang masuk dalam kategori sangat baik sebanyak 0 siswa atau sebesar $0 \%$, kategori baik sebanyak 2 siswa atau sebesar $6,9 \%$, kategori sedang sebanyak 8 siswa atau sebesar 27,6\%, kategori kurang sebanyak 16 siswa atau sebesar 55,2\% dan kategori sangat kurang sebanyak 3 siswa atau sebesar $10,3 \%$.

\section{SD Negeri 02 Kota Bengkulu}

Tabel 7. Deskriptif hasil penelitian siswa kelas V SD N 02 Laki-laki

\begin{tabular}{c|c|c|c} 
Skor & kategori & frekuensi & $\mathbf{\%}$ \\
\hline $19-21$ & Sangat baik & 0 & 0 \\
\hline $16-18$ & Baik & 0 & 0 \\
\hline $13-15$ & sedang & 0 & 0 \\
\hline $10-12$ & kurang & 2 & 10 \\
\hline$\leq 9$ & $\begin{array}{l}\text { Sangat } \\
\text { kurang }\end{array}$ & 18 & 90 \\
\hline \multicolumn{2}{r|}{ Jumlah } & 20 & 100
\end{tabular}

laki-laki bahwa hasil tes kemampuan kids athletics yang masuk dalam kategori sangat baik sebanyak 0 siswa atau sebesar $0 \%$, kategori Baik sebanyak 0 siswa atau sebesar $0 \%$, kategori sedang sebanyak 0 siswa atau sebesar 0\%, kategori kurang sebanyak 2 siswa atau sebesar $10 \%$, dan kategori sangat kurang sebanyak 18 siswa atau sebesar $90 \%$.

Tabel 8. Deskriptif hasil penelitian siswa kelas v SD N 02 perempuan

\begin{tabular}{c|c|c|c} 
Skor & Kategori & frekuensi & $\mathbf{\%}$ \\
\hline $18-20$ & Sangat baik & 0 & 0 \\
\hline $15-17$ & Baik & 0 & 0 \\
\hline $12-14$ & Sedang & 1 & 5 \\
\hline $9-11$ & Kurang & 8 & 40 \\
\hline$\leq 8$ & Sangat kurang & 11 & 55 \\
\hline \multicolumn{2}{r|}{ Jumlah } & 20 & 100
\end{tabular}

perempuan bahwa hasil tes kemampuan kids athletics yang masuk dalam kategori sangat baik sebanyak 0 siswa atau sebesar $0 \%$, kategori baik sebanyak 0 siswa atau sebesar $0 \%$, kategori sedang sebanyak 1 siswa atau sebesar 5\%, kategori kurang sebanyak 8 siswa atau sebesar $40 \%$ dan kategori sangat kurang sebanyak 11 siswa atau sebesar $55 \%$.

Tabel 9. hasil penelitian kids athletics siswa

\begin{tabular}{c|c|c|c}
\multicolumn{4}{c}{ kelas V SD N 02 Kota Bengkulu } \\
N0 & Kategori & frekuensi & \% \\
\hline 1 & Sangat baik & 0 & 0 \\
\hline 2 & Baik & 0 & 0 \\
\hline 3 & Sedang & 1 & 2.5 \\
\hline 4 & Kurang & 10 & 25 \\
\hline 5 & Sangat kurang & 29 & 72,5 \\
\hline & Jumlah & 40 & 100
\end{tabular}

hasil gabungan anak laki-laki dan perempuan bahwa hasil tes kemampuan kids athletics siswa kelas V SD Negeri 02 Kota Bengkulu yang masuk dalam kategori sangat baik sebanyak 0 siswa atau sebesar $0 \%$, kategori baik sebanyak 0 siswa atau sebesar $0 \%$, kategori sedang sebanyak 1 siswa atau sebesar 2,5\%, kategori kurang sebanyak 10 siswa atau sebesar $25 \%$ dan kategori sangat 
kurang sebanyak 29 siswa atau sebesar $72,5 \%$.

4. SD Negeri 01 Kota Bengkulu

Tabel 10. Deskriptif hasil penelitian siswa kelas V SD N 01 Laki-laki

\begin{tabular}{c|c|c|c} 
Skor & Kategori & frekuensi & $\mathbf{\%}$ \\
\hline $19-21$ & Sangat baik & 0 & 0 \\
\hline $16-18$ & Baik & 0 & 0 \\
\hline $13-15$ & Sedang & 0 & 0 \\
\hline $10-12$ & Kurang & 1 & 9,1 \\
\hline$\leq 9$ & $\begin{array}{l}\text { Sangat } \\
\text { kurang }\end{array}$ & 10 & 90.1 \\
\hline \multicolumn{2}{r}{ Jumlah } & 11 & 100
\end{tabular}

untuk laki-laki bahwa hasil tes kemampuan kids yang masuk dalam kategori sangat baik sebanyak 0 siswa atau sebesar $0 \%$, kategori Baik sebanyak 0 siswa atau sebesar $0 \%$, kategori cukup sebanyak 0 siswa atau sebesar $0 \%$, kategori kurang sebanyak 1 siswa atau sebesar 9,1\%, dan kategori sangat kurang sebanyak 10 siswa atau sebesar $90,9 \%$

Tabel 11 Deskriptif hasil penelitian siswa kelas v SD N 01 perempuan

\begin{tabular}{c|c|c|c} 
Skor & Kategori & frekuensi & $\mathbf{\%}$ \\
\hline $18-20$ & Sangat baik & 0 & 0 \\
\hline $15-17$ & Baik & 0 & 0 \\
\hline $12-14$ & sedang & 1 & 5 \\
\hline $9-11$ & kurang & 8 & 40 \\
\hline$\leq 8$ & $\begin{array}{l}\text { Sangat } \\
\text { kurang }\end{array}$ & 11 & 55 \\
\hline \multicolumn{2}{r|}{ Jumlah } & 20 & 100
\end{tabular}

untuk perempuan bahwa hasil tes kemampuan kids athletics yang masuk dalam kategori sangat baik sebanyak 0 siswa atau sebesar $0 \%$, kategori baik sebanyak 0 siswa atau sebesar $0 \%$, kategori sedang sebanyak 1 siswa atau sebesar 8,3\%, kategori kurang sebanyak 4 siswa atau sebesar 33,3\% dan kategori sangat kurang sebanyak 7 siswa atau sebesar $58,3 \%$
Tabel 12 hasil penelitian kids athletics siswa kelas V SD N 01 Kota Bengkulu

\begin{tabular}{c|c|c|c} 
No & Kategori & frekuensi & $\mathbf{\%}$ \\
\hline 1 & Sangat baik & 0 & 0 \\
\hline 2 & Baik & 0 & 0 \\
\hline 3 & Sedang & 1 & 4,3 \\
\hline 4 & Kurang & 5 & 21,7 \\
\hline 5 & Sangat kurang & 17 & 73,9 \\
\hline \multicolumn{2}{r|}{ Jumlah } & 23 & 100
\end{tabular}

hasil gabungan anak laki-laki dan perempuan bahwa hasil tes kemampuan kids athletics siswa kelas V SD Negeri 01 Kota Bengkulu yang masuk dalam kategori sangat baik sebanyak 0 siswa atau sebesar $0 \%$, kategori baik sebanyak 0 siswa atau sebesar $0 \%$, kategori sedang sebanyak 1 siswa atau sebesar 4,3\%, kategori kurang sebanyak 5 siswa atau sebesar $21,7 \%$ dan kategori sangat kurang sebanyak 17 siswa atau sebesar $73,9 \%$.

5. Hasil tes kemampuan Kids Athletics seluruh sekolah dasar kota bengkulu

Tabel 13 hasil penelitian kids athletics siswa seluruh sekolah dasar Kota Bengkulu

\begin{tabular}{c|c|c|c} 
N0 & Kategori & frekuensi & $\mathbf{\%}$ \\
\hline 1 & Sangat baik & 0 & 0 \\
\hline 2 & Baik & 4 & 3,1 \\
\hline 3 & Sedang & 21 & 16,3 \\
\hline 4 & Kurang & 46 & 35,7 \\
\hline 5 & $\begin{array}{l}\text { Sangat } \\
\text { kurang }\end{array}$ & 58 & 44,9 \\
\hline \multicolumn{2}{|c|}{ Jumlah } & 129 & 100
\end{tabular}

Dilihat dari seluruh sekolah dasar Kota Bengkulu bahwa hasil tes kemampuan kids athletics yang masuk dalam kategori sangat baik sebanyak 0 siswa atau sebesar $0 \%$, kategori baik sebanyak 4 siswa atau sebesar $3,1 \%$, kategori sedang sebanyak 21 siswa atau sebesar 16,3\%, kategori kurang sebanyak 46 siswa atau sebesar 35,7\% dan 
kategori sangat kurang sebanyak 58 siswa atau sebesar $44,9 \%$.

\section{Pembahasan}

Munurut Suyono (2002:5) Kid's athletics adalah cabang olahraga atletik khusus untuk anak-anak yang di lakukan secara individu maupun kelompok dalam bentuk perlombaan sehingga melatih anak untuk berkompetisi dalam permainan yang menyenangkan

Dari hasil penelitian kemampuan Kid's athletics pada siswa sekolah dasar yaitu Dapat dikatakan bahwa pada SD Negeri 19 Kota Bengkulu berkategori "kurang" atau sebesar 40,5\%, karena kemampuan guru yang kurang ahli dalam cabang Kids Athletics dan guru juga belum mengenalkan kepada siswa nomor-nomor perlombaan kids athletics. Dapat dikatakan bahwa kemampuan Kids Athletics SD Negeri 74 berkategori "kurang" atau sebesar 55,2\%, karena kemampuan siswa yang kurang maksimal dalam melakukan tes dan juga pembalajaran Kids Athletics belum ada didalam kurikulum jadi guru tidak mengenalkan pembelajran Kids Athletics, guru hanya mengajarkan gerakan dasar saja. Dapat dikatakan kemampuan kids athletics SD Negeri 02 Kota Bengkulu berkategori "sangat kurang" atau sebesar 72,5\% ,dikarenakan sekolah ini masih kurangnya sarana dan prasarananya, juga pembalajaran Kids Athletics belum ada didalam kurikulum jadi guru tidak mengenalkan pembelajran Kids Athletics, guru hanya mengajarkan gerakan dasar saja. Dapat dikatakan kemampuan kids athletics SD Negeri 01 Kota Bengkulu berkategori "sangat kurang" atau sebesar 73,9\%, karena guru disekolah tersebut tidak mengenalkan Kids athletics dalam pembelajaran PJOK dan siswa pun banyak yang kurang maksimal dalam pelaksanaan test tersebut. Dapat dikatakan untuk kemampuan seluruh Sekolah Dasar Kota Bengkulu kemampuan kids athletics berkategori kurang atau sebesar 35,\% dan sangat kurang atau sebesar $44,9 \%$. Dari hasil yang dapat bahwa kemampuan Kid's athletics pada siswa sekolah dasar di Kota Bengkulu banyak faktor yang mempengaruhi yaitu kurang sarana dan prasarana yang ada disetiap sekolah walaupun ada peralatan tidak diperkenalkan dengan anak-anak, belum adanya pembinaan disekolah, dan belum adanya pengenalan kids athletics dalam pembelajaran PJOK, tetapi Pada dasarnya siswa mempunyai kemampuan gerak dasar seperti lari ,lompat lempar dan daya tahan.

\section{PENUTUP}

\section{Simpulan}

Dapat kita simpulkan bahwa Kemampuan Kid's athletics pada SD Negeri 19 Kota Bengkulu anak laki-laki berkategori "kurang" atau sebesar $46,7 \%$, sedangkan anak perempuan berkategori " sedang " atau sebesar 36,4\%. Kemampuan Kid's athletics pada SD Negeri 74 Kota Bengkulu anak lakilaki berkategori "kurang" atau sebesar $56,25 \%$, sedangkan anak perempuan berkategori "kurang" atau sebesar 53,8\%. Kemampuan Kid's athletics pada SD Negeri 02 Kota Bengkulu anak laki-laki berkategori "sangat kurang" atau sebesar 90\% , sedangkan anak perempuan "sangat kurang" atau sebesar 55\%. Kemampuan Kid's athletics pada SD N 01 Kota Bengkulu anak laki-laki berkategori " sangat kurang" atau sebesar 90,9\%, sedangkan anak perempuan berkategori "sangat kurang" atau sebesar 58,3\%. Kemampuan Kid's athletics seluruh sekolah dasar di Kota Bengkulu berkategori “ sangat kurang " atau sebesar $44,9 \%$. 


\section{Saran}

Hasil dari penelitian dan kesimpulan diatas, maka penulis mengajukan saransaran sebagai berikut:

1. Penulis memberikan saran agar selama mengikuti tes siswa lebih dapat bersungguh -sungguh dan seoptimal mungkin untuk mencapai hasil yang maksimal.

2. Bagi siswa agar lebih meningkatkan kemampuan gerak dasar seperti lari, lempar, lompat dan daya tahan.

3. Semua rangkaian tes masih perlu mendapatkan perhatian yang khusus (tambahan jam) dari guru penjas agar siswa lebih mendapatkan wawasan yang luas terkait dengan Kids athletics, sehingga nantinya siswa akan lebih trampil dan berprestasi.

\section{DAFTAR PUSTAKA}

Allen, Eileen K and Marotz, R Lynn. (2013). Profil Perkembangan Anak Prakelahiran Hingga Usia 12 Tahun. Jakarta : PT Indeks.

Dr.H.Sutirna, M.Pd. (2013). Perkembangan \& Pertumbuhan Peserta Didik. Yogyakarta : CV.ANDI OFFSET.

Dwi Taufik Saputro. (2014). Kemampuan Kids Athletics kelas IV dan V SD
Negeri Bagusan Kecematan Selopampang Kabupaten Temanggung. Skripsi. Fakultas Ilmu Keolahragaan Universitas Negeri Yogakarta.

Kemendikbud. (2010). Pedoman Olimpiade Olahraga Siswa Nasional III (O2SN III) Sekolah Dasar Tahun 2010. Jakarta : Kemendikbud.

Nuryati, Arwin, dan Bogy. 2017. "Upaya Peningkatan Proses Belajar Atletik Tolak Peluru Melalui Penerapan Media POA Pada Siswa Kelas V SD Negeri 05 Kota Bengkulu". Jurnal Kinestetik, Vol. 1 (2).

Kemendikbud. (2005) .Bimbingan Teknis Pembinaan Club Olahrga SD.

Sugiyono. (2012). Metode Penelitian Kuantitatif Kualitatif Dan $R \& D$. Bandung : Alfabeta.

Suharsimi, Arikunto. (2010). Prosedur Penelitian Suatu pendekatan Praktik. Jakarta : PT Bineka Cipta.

Suyono. (2002). IAAF Kids' Athletics. Jakarta : Staff Set-IAAF RDC Jakarta. 